\title{
Decrease of Grip Strength is Associated with Progression of Sleep Disturbance in Chronic Liver Diseases
}

\author{
Hiroki Nishikawa ${ }^{1}$, Kazunori Yoh ${ }^{1}$, Hirayuki Enomoto ${ }^{2}$, Takashi Nishimura ${ }^{1}$, Shuhei \\ Nishiguchi ${ }^{1}$, and Hiroko Iijima ${ }^{2}$ \\ ${ }^{1}$ Affiliation not available \\ ${ }^{2}$ Hyogo Coll Med
}

October 24, 2020

\begin{abstract}
Background and aims: The causal relationship between sarcopenia and sleep disorder in patients with chronic liver disease (CLDs) is unclear. We aimed examine the influence of sarcopenia-related factors (grip strength (GS) and muscle mass) on the progression of sleep disorder in patients with chronic liver disease $(\mathrm{n}=182,46$ cirrhotic cases, median age $=64$ years). Methods: Sleep quality was evaluated by the Japanese version of Pittsburgh Sleep Quality Index (PSQI-J). PSQI-J >6 points was defined as sleep disorder. In all analyzed patients, evaluation using PSQI-J questionnaire was performed twice or more during the follow-up period. Time interval from the date of baseline PSQI-J and the first confirmed date of elevation of PSQI-J score was calculated. Our primary endpoint was the elevation of PSQI-J score compared to the baseline PSQI-J score. GS decline was diagnosed with a GS of $<26 \mathrm{~kg}$ for male and $<18 \mathrm{~kg}$ for female. Loss of muscle mass was diagnosed by a skeletal muscle index of $<7.0 \mathrm{~kg} / \mathrm{m} 2$ for male and $<5.7 \mathrm{~kg} / \mathrm{m} 2$ for female on bioelectrical impedance analysis. Results: The median PSQI-J score was 5. PSQI-J $>6$ points at baseline was found in 83 patients (45.6\%). In patients with GS decline $(\mathrm{n}=48)$, the 3 -year cumulative elevation rate of PSQI-J score was $82.4 \%$, while in patients with GS non-decline, that was $36.2 \%(\mathrm{P}<0.0001)$. In patients with SMI decline $(\mathrm{n}=64)$, the 3-year cumulative elevation rate of PSQI-J score was 60.6\%, while in patients with SMI non-decline, that was $43.4 \%(\mathrm{P}=0.1822)$. On the multivariate analysis of factors associated with the elevation of PSQI-J score, only GS decline $(\mathrm{P}=0.0002)$ was a significant factor. Conclusions: Reduced GS rather than loss of muscle mass is independently associated with an elevated risk for the progression of sleep disorder in CLD patients.
\end{abstract}

\section{Hosted file}

Mainbody PSQI IJCP.pdf available at https://authorea.com/users/369840/articles/488656decrease-of-grip-strength-is-associated-with-progression-of-sleep-disturbance-inchronic-liver-diseases

\section{Hosted file}

Table 1.pdf available at https://authorea.com/users/369840/articles/488656-decrease-of-gripstrength-is-associated-with-progression-of-sleep-disturbance-in-chronic-liver-diseases

\section{Hosted file}

Table 2.pdf available at https://authorea.com/users/369840/articles/488656-decrease-of-gripstrength-is-associated-with-progression-of-sleep-disturbance-in-chronic-liver-diseases

\section{Hosted file}

Table 3.pdf available at https://authorea.com/users/369840/articles/488656-decrease-of-gripstrength-is-associated-with-progression-of-sleep-disturbance-in-chronic-liver-diseases 


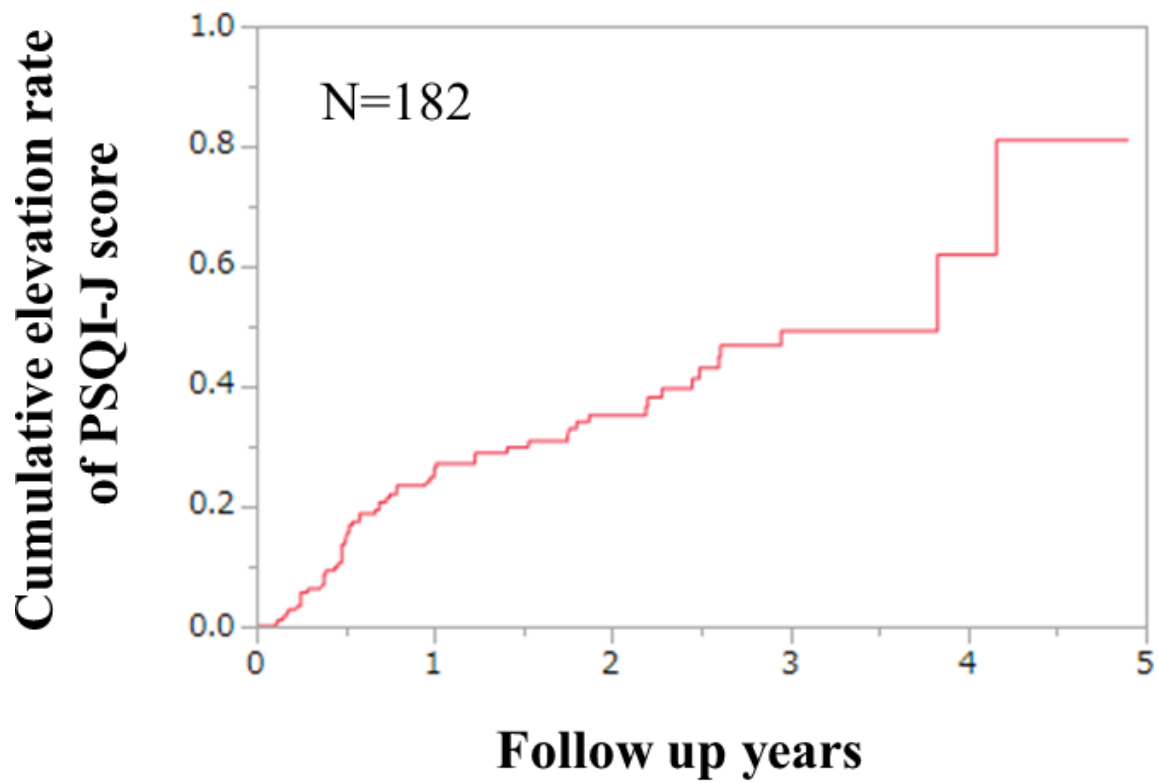

Figure 1
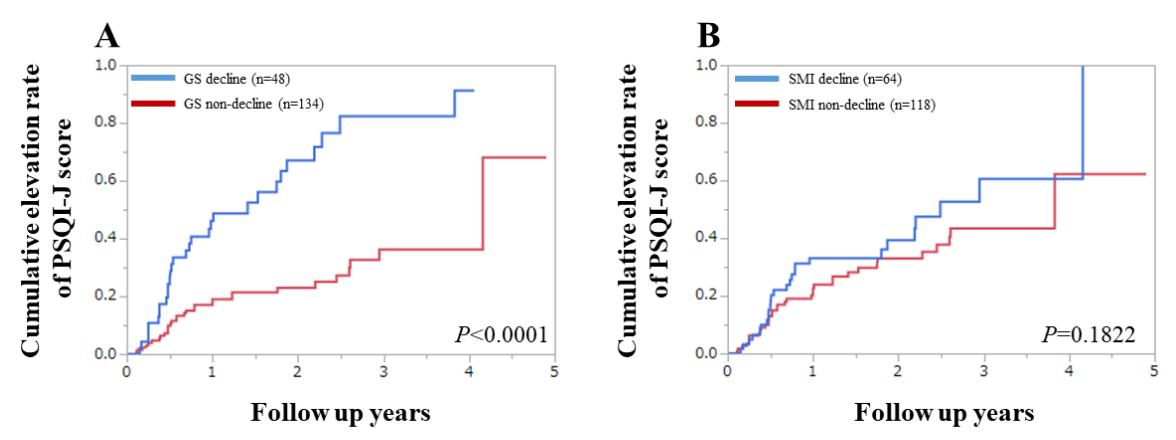

Figure 2 

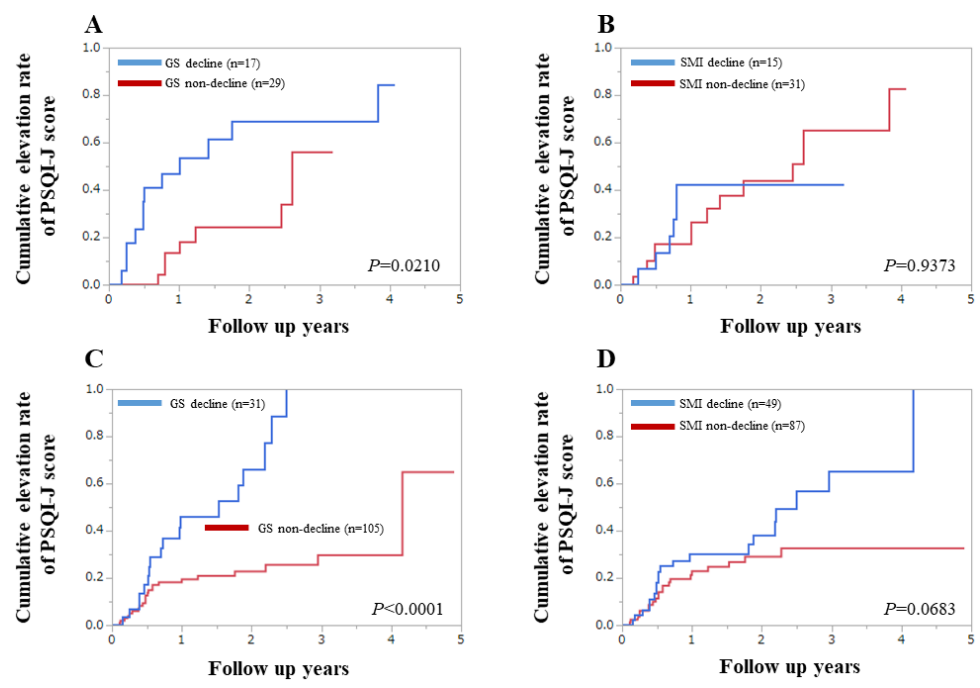

Figure 3
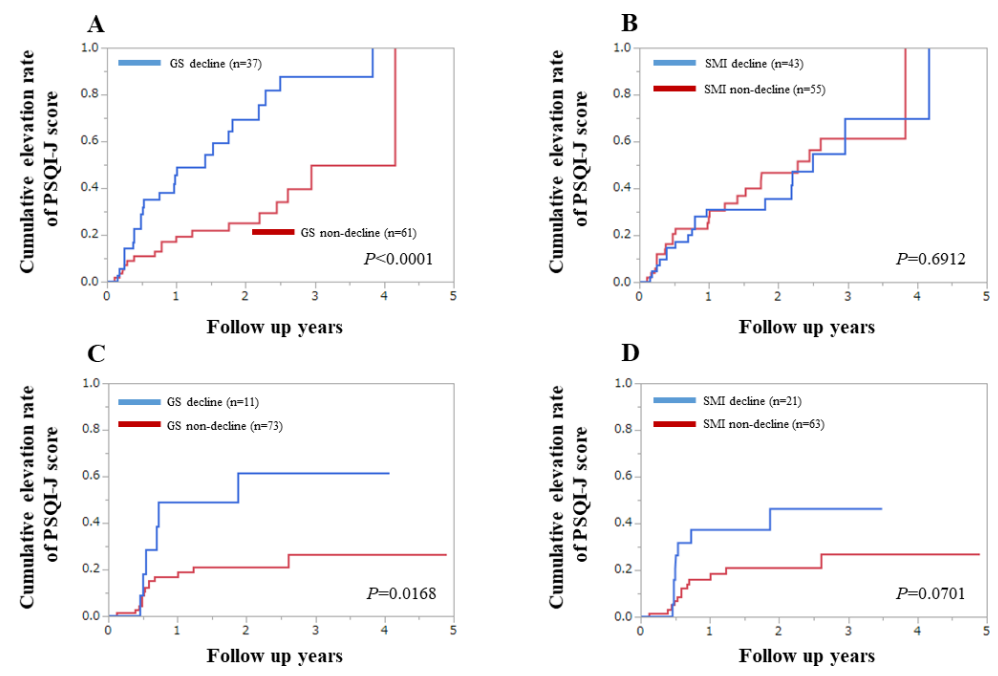

Figure 4
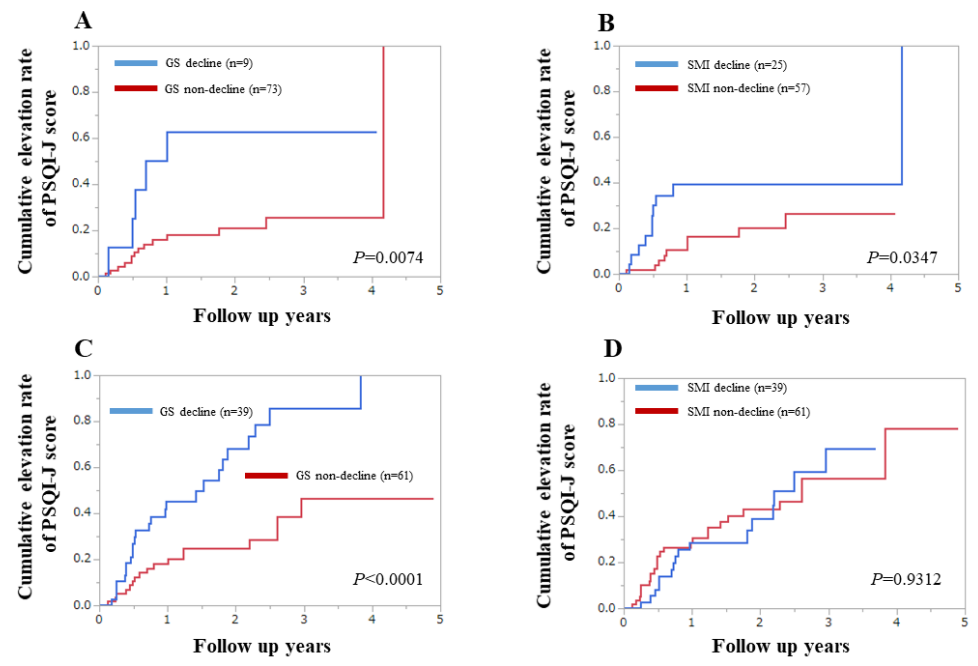

Figure 5 

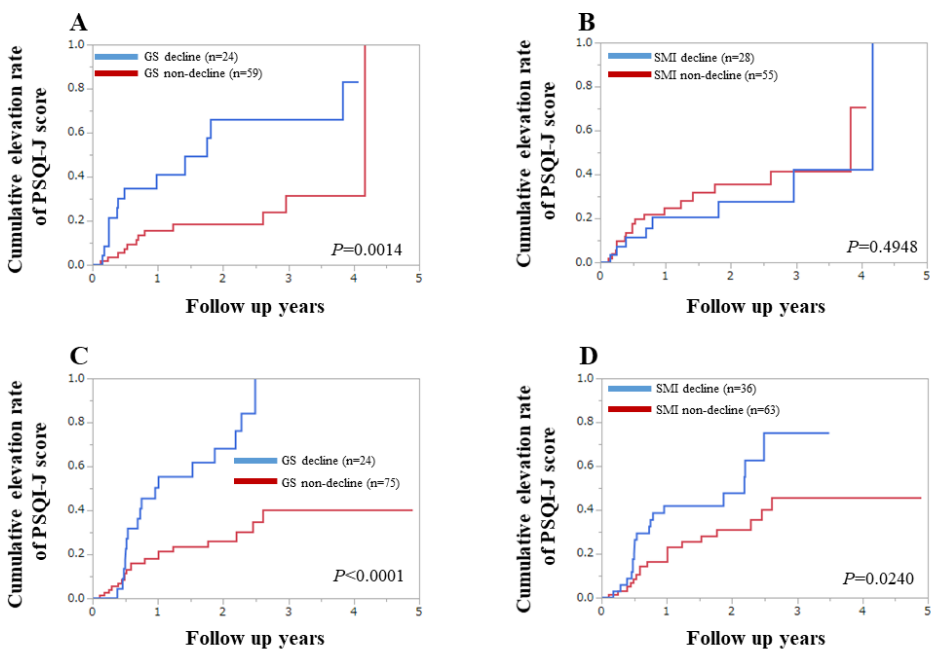

Figure 6 